\title{
DEVELOPMENT AND VALIDATION OF A STORM SURGE AND WAVE MODEL FOR LAKE HURON (GREAT LAKES, USA)
}

\author{
Michael Salisbury, P.E., Atkins, Michael.Salisbury@atkinsglobal.com \\ Todd DeMunda, P.E., Atkins, Todd.DeMunda@atkinsglobal.com \\ Nicole Walker, P.E., Atkins, Nicole.Walker@atkinsglobal.com
}

The Federal Emergency Management Agency (FEMA) is tasked with developing flood insurance rate maps along coastlines and major water bodies within the United States, which includes the U.S. portion of the Great Lakes shoreline. Previous flood studies have developed storm surge and wave models of the Great Lakes (including Lake Huron) in support of FEMA's efforts; however, an independent technical review of those previous coastal flood studies in Lake Huron revealed technical deficiencies in the methods and tools used to generate the wave conditions needed to support overland mapping. Most paramount of these was the fact that starting wave conditions for one dimensional (1D) transformation from a two-dimensional (2D) model were taken from deep water. Using 1D methods to shoal and refract waves to the coastline for runup and/or overland wave analysis may fail to capture the more complex nature of wave refraction/diffraction that $2 \mathrm{D}$ wave models can capture. Further, this method omits the development of the directional wave spectra in the nearshore region. To address this concern, a coupled 2D wave and water level model (ADCIRC+SWAN) was developed to hindcast historical storms that have occurred in Lake Huron. These model results will be used to drive the $1 \mathrm{D}$ methods to assess nearshore wave hazards from locations near the surfzone limit.

The ADCIRC+SWAN mesh (Figure 1) covers the entirety of Lake Huron and Lake Michigan, with boundaries at the junction with Lake Superior at Soo Locks near Sault Ste. Marie, MI, and at the mouth of the St. Clair River near Port Huron, MI. It was necessary to include Lake Michigan in the model domain to allow the two lakes to exchange flow through the Straits of Mackinac, which is critical to accurately simulate storm surge in Lake Huron. The final ADCIRC+SWAN mesh contained 1,298,483 elements and 667,396 nodes with grid resolution varying between 14 kilometers in the center of Lake Michigan to 15 meters at the most detailed locations along the shoreline of Lake Huron. The model was forced by hindcast spatially-varying wind and atmospheric pressure fields.

Prior to validation, a sensitivity analysis was performed on key model parameters for both ADCIRC and SWAN. These parameters represented a combination of both physical and numerical properties for each model node. The primary purpose of these sensitivity analyses was to produce accurate results while balancing the computational expense of the model. Due to the high resolution in the model and the total number of storm events selected for analysis (151), the simulation runtime is a practical concern for the production phase of this project. In the end, a combination of parameter values was identified that maintained accuracy while significantly improving the simulation runtimes (a 63\% reduction in computational expense).
The model was validated for both water levels and waves (Figure 2) using a total of 10 historical storm events. These 10 events provided a comprehensive sampling of the overall storm event population dataset by representing a variety of time periods, initial conditions, and forcing mechanisms, and as such provided a thorough test bed for model validation purposes. Overall, the model recreates the historical data with a high degree of fidelity and very little bias. From these results, it's concluded that the model described herein is sufficient to simulate storm surge and wave conditions for the purposes of updating coastal flood maps for U.S. counties along the shoreline of Lake Huron.

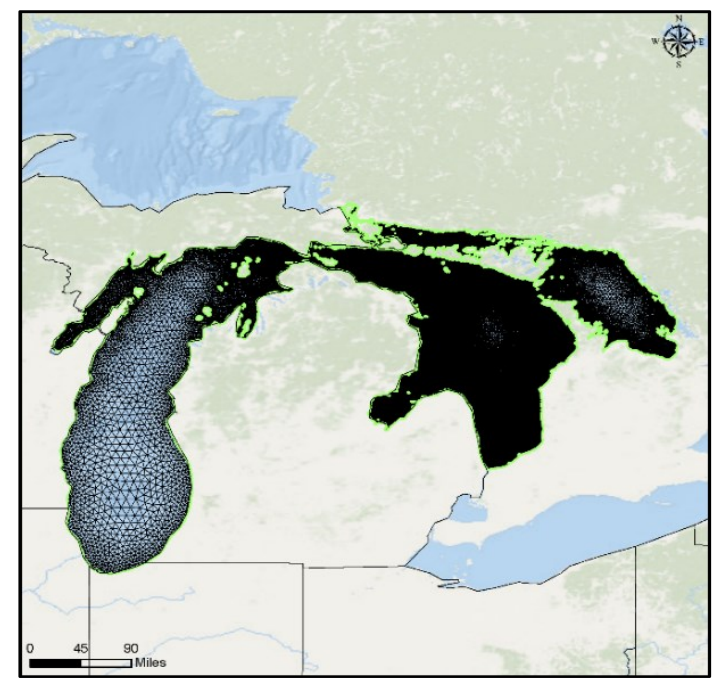

Figure 1. Lake Huron ADCIRC+SWAN model domain.

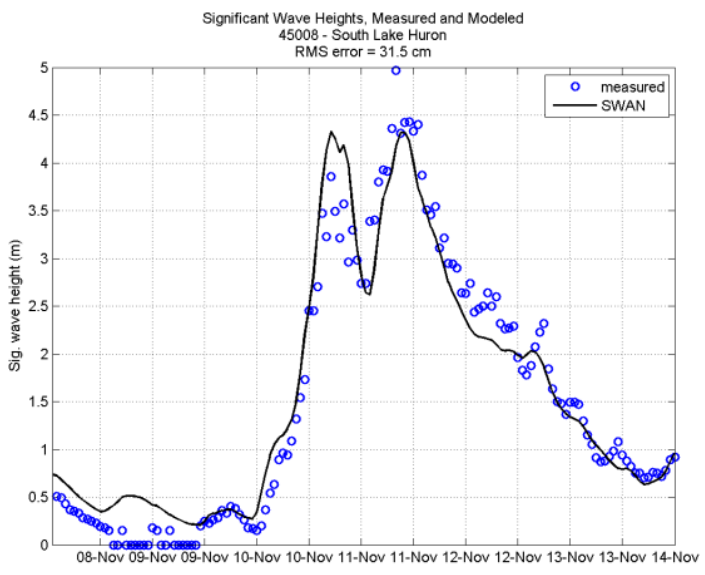

Figure 2. Significant wave height results for the November 10, 1998 storm event 